\title{
OS REFLEXOS DA PÓS-MODERNIDADE NOS CONFLITOS FAMILIARES: A MEDIAÇÃO EM BUSCA DA PROTEÇÃO À DIGNIDADE DA PESSOA HUMANA E DOS DIREITOS DA PERSONALIDADE
}

\author{
Ana Elisa Silva Fernandes ${ }^{1}$ \\ Cleide Aparecida Gomes Rodrigues Fermentão ${ }^{2}$
}

\section{Resumo:}

O artigo científico tem o objetivo de investigar os reflexos da pós-modernidade nos conflitos familiares e propor a mediação como meio adequado de solução de conflitos familiares na proteção da dignidade da pessoa humana e dos direitos da personalidade. Para tanto, o método a ser utilizado será o dedutivo, por meio de revisão bibliográfica. Devido ao caráter subjetivo que os conflitos familiares carregam, a mediação demonstra-se como método adequado para resolução de conflitos ao oportunizar aos sujeitos a responsabilidade por suas ações, transpondo as marcas do individualismo da sociedade pós-moderna.

Palavras-chave: Pós-modernidade; Conflitos familiares; Mediação familiar; Resolução adequada de conflitos; Dignidade da pessoa humana

\section{THE REFLECTIONS OF POST-MODERNITY IN FAMILY CONFLICTS: MEDIATION IN SEARCH OF PROTECTION TO THE DIGNITY OF THE HUMAN PERSON AND PERSONALITY RIGHTS}

\begin{abstract}
:
The scientific article aims to investigate the reflexes of post-modernity in family conflicts and to propose mediation as an adequate means of solving family conflicts in the protection of the dignity of the human person and the rights of the personality. For that, the method to be used will be the deductive one, through bibliographic review. Due to the subjective character that family conflicts carry, mediation proves to be an adequate method for resolving conflicts by giving subjects the responsibility for their actions, transposing the marks of individualism in postmodern society.
\end{abstract}

Keywords: Postmodernity; Family conflicts; Family mediation; Adequate conflict resolution; Dignity of human person

\section{INTRODUÇÃO}

\footnotetext{
${ }^{1}$ Mestranda em Ciências Jurídicas com ênfase em Direitos da Personalidade pela UNICESUMAR. Bolsista no Programa de Suporte à Pós-Graduação de Instituições de Ensino Particulares PROSUP/CAPES (módulo Bolsas) pelo Programa de Pós-Graduação em Ciências Jurídicas na UNICESUMAR. Membra do grupo de Pesquisa: "Proteção Integral da Pessoa: Interações dos Direitos Humanos, dos Direitos Fundamentais e dos Direitos da Personalidade". Graduada em Direito pela Pontifícia Universidade Católica do Paraná. E-mail: annaefernandes@gmail.com.

${ }^{2}$ Doutora nas relações sociais - direito civil - pela UFPR Universidade Federal do Paraná, pós doutora pela UNISINOS - Universidade Vale do Rio dos Sinos-RS, graduação e mestrado em direito civil pela UEM Universidade Estadual de Maringá, pesquisadora do ICETI, professora da graduação e Programa de Mestrado e Doutorado da UNICESUMAR, membro do IBDFAM e o Instituto dos Advogados do Paraná (IAP). Advogada. E-mail: cleidefermentao@gmail.com
} 
A contemporaneidade consiste em um reflexo das transformações sociais vivenciadas nas sociedades modernas que tiveram o principal objetivo de resguardar integralmente a pessoa humana e sua dignidade. Essas mudanças sociais buscaram efetivar os direitos e liberdades dos indivíduos e refletiram nos mais diversos âmbitos da sociedade, inclusive na família. A proteção integral ao indivíduo, tornou-se o propósito das sociedades contemporâneas, inclusive dentro de sua relação familiar. Assim, considerando que a família consiste em um fato histórico, jurídico e social articulado de acordo com as influências da sociedade em que está inserida, e o que a realidade contemporânea se transformou nas últimas décadas, eis a importância da discussão da temática.

O objetivo da pesquisa consiste em investigar quais são os reflexos da pósmodernidade nos conflitos familiares, e propor a mediação como meio adequado de solução de conflitos familiares na proteção da dignidade da pessoa humana, e dos direitos da personalidade.

Diante estas premissas, a presente pesquisa buscará respostas para os seguintes questionamentos: As transformações sociais refletem nas relações familiares e na existência de conflitos familiares? É possível dizer que a mediação proporciona a pacificação e solução para os conflitos familiares em defesa da dignidade da pessoa humana assim como aos direitos da personalidade dos envolvidos? Pode-se dizer que a mediação se trata do meio adequado de tratamento de conflitos familiar na contemporaneidade?

Para responder aos questionamentos, primeiramente, serão analisados o fenômeno da modernidade e da pós-modernidade e seus reflexos no mundo contemporâneo sob a perspectiva das teorias desenvolvidas por Anthony Giddens e Gilles Lipovetsky, com contribuições das ideias de Boaventura de Sousa Santos e Zygmunt Bauman.

Em um segundo momento, serão analisadas as noções de conflito e a complexidade social pós-moderna; a construção da definição a respeito do conflito, que percorre duas noções principais: a primeira, de que o conflito se trata de uma patologia social, e a oposta, de que o conflito é um fenômeno natural e intrínseco dos relacionamentos humanos marcados pela complexidade. Ademais, serão investigados os efeitos das mudanças culturais e sociais na pós- modernidade nas relações familiares, em particular, o surgimento de conflitos familiares que dão ensejo aos processos judiciais.

No último capítulo, enfim, como forma de proteção integral a pessoa, e, em 
proteção da dignidade da pessoa humana, será analisada a mediação como método de solução de conflitos que decorrem da sociedade pós-moderna.

O método a ser utilizado será o dedutivo, por meio de revisão bibliográfica, com a pesquisa de artigos, dissertações e livros, sejam eles físicos, provenientes de revistas eletrônicas nacionais ou contidos em plataformas brasileiras, com o fim de verificar qual o tratamento e entendimento atribuído pelas áreas de Sociologia e Direito às questões em foco no artigo, especificamente, os temas de Pós-modernidade, Modernidade, Conflitos, Direito de família e Mediação familiar.

\section{A PÓS-MODERNIDADE E SEUS EFEITOS NO MUNDO CONTEMPORÂNEO}

Uma das chaves para compreender a pós-modernidade está no pensamento de autores como Anthony Giddens, Gilles Lipovetsky, assim como as contribuições de Boaventura de Sousa Santos e Zygmunt Bauman. Estes autores descrevem características da sociedade contemporânea.

Na interpretação de Anthony Giddens, a sociedade contemporânea vivencia um processo de modernidade tardia, alta modernidade ou modernidade radical e identifica a modernidade como o "estilo, costume de vida ou organização social que emergiram na Europa a partir do século XVII e que ulteriormente se tornaram mais ou menos mundiais em sua influência." (GIDDENS, 1991, p. 11).

No século XX, as instituições têm um dinamismo acelerado: são impactadas e impactam processos em nível global. O mesmo acontece com os indivíduos que, independentemente do quão local sejam os contextos específicos da ação, “contribuem para (e promovem diretamente) as influências sociais que são globais em suas consequências e implicações" (GIDDENS, 2002, p. 9). A partir do final do século XX muitos teóricos defenderam que a sociedade estava vivendo uma época além da própria modernidade, como um novo sistema social, uma espécie de sociedade do consumo ou sociedade da informação, em decorrência da evolução dos meios de comunicação e das novas tecnologias. No século XXI, a modernidade estaria terminada, sobrevindo a pós-modernidade, uma espécie de sociedade pós- industrial (GIDDENS, 1991, p. 11).

Não há como falar em pós-modernidade, pois não houve uma ruptura completa com as tradições da modernidade, mas sim um maior dinamismo, amplitude e profundidade dos 
processos de modernidade. A sociedade atual está vivenciando um período em que as consequências da modernidade estão exacerbadas, mais radicais e universais como nunca estiveram. Para o autor, existem características da sociedade atual que indicam contornos de pós-modernidade, mas em sua interpretação, trata-se de um momento histórico bem diferente da definição que muitos autores atribuem à pós-modernidade. Sendo assim, entende que “[...] as instituições sociais modernas são, sob alguns aspectos, únicas - diferentes em forma de todos os tipos de ordem tradicional. [...]" (GIDDENS, 1991, p. 13).

O maior dinamismo, amplitude e profundidade do processo de modernidade afetou as práticas sociais e os modos de comportamento na sociedade em uma escala global, assim, defende que houve um desencaixe, uma separação entre os espaços naturais, que caracteriza as sociedades modernas contemporâneas: a separação entre espaço e tempo.

Anthony Giddens (1991) descreve que é a partir da noção de desencantamento do mundo moderno, desenvolvida por Max Weber - em que o mundo, a sociedade deixou de ser um ambiente tomado pela religião e tornou-se em um lugar de leis abstratas, racional, em que os indivíduos podem prever e manipular -, que houve um desencaixe, uma separação entre o tempo e o espaço nas sociedades contemporâneas. O que identifica a modernidade, portanto, não seria somente o industrialismo e o capitalismo. O que verdadeiramente interessa para a modernidade seria a precisão de tempo que é deslocada dos espaços naturais, realizada por meio dos mecanismos de desencaixes. Em sua obra, o autor (1991) identifica dois mecanismos de desencaixe entre tempo e espaço: as fichas simbólicas e os sistemas peritos. ${ }^{3}$ Toda a construção a respeito da modernidade e pós-modernidade em Giddens parte das ideias acima desenvolvidas.

Os impactos desses elementos da modernidade tardia na vida cotidiana dos indivíduos, que são inescapáveis, encerram a todos em um mundo de dúvida radical e múltiplas fontes de autoridade. A construção do eu e da identidade é feita de forma reflexiva (os indivíduos sabem o que estão fazendo e por que estão fazendo, porquanto podem assumir maior consciência de suas atitudes), mas dentro de uma miríade de opções e de possibilidades de agir. Trata-se de um mundo de possibilidades nunca vistas no contexto

\footnotetext{
${ }^{3}$ Embora noções mais aprofundadas a respeito das fichas simbólicas e dos sistemas peritos sejam importantes na obra de Anthony Giddens, a presente pesquisa não tem por objetivo aprofundar em tais questões. Inobstante, identifica-se que a fichas simbólicas são meios de intercâmbio que independem de características de um grupo particular para existir, mas que só atua em relações que há igualdade. Como exemplos de fichas simbólicas, Giddens discute o dinheiro e o processo de eleição em regimes democráticos. Sistemas peritos seriam ambientes onde há uma grande ênfase técnica, na excelência profissional.
} 
tradicional. Giddens utiliza como exemplo dessas transformações o estudo "Segunda chance", de Wallerstein e Blakeslee, sobre o divórcio e o casamento, que aponta a problemática das novas possibilidades das chamadas novas famílias, diferenciadas das famílias tradicionais. Trata-se de um novo mundo gerador de ansiedades, nos quais os riscos são calculados e que exigem constantes adaptações (GIDDENS, 2002).

Anthony Giddens enfatiza os desafios da modernidade tardia, dentre eles, a dificuldade na busca de consenso e de soluções para problemas comuns, tarefa que envolve o fim da desigualdade e da exploração e uma nova construção de princípios éticos, morais locais e globais. O grande dilema reside na conciliação das escolhas e possibilidades individuais com um futuro comum, em uma sociedade cada vez mais produto de uma lógica mercantilizada e excludente. (GIDDENS, 2002).

As transformações da sociedade contemporânea também são abordadas por Gilles Lipovetsky, cujo pensamento se constrói em torno da ideia de hipermodernidade. Diferentemente de outros autores, para o autor, a pós-modernidade não significa o fim da modernidade ${ }^{4}$, mas uma versão exacerbada de algumas de suas características, como o desenvolvimento técnico e a valorização do individualismo. Por isso, adota a expressão "hipermodernidade" para se referir a esse processo, que em seu entendimento refere-se à exacerbação dos valores da modernidade, como a cultura do excesso determinada e marcada pelo efêmero em que o sujeito, freneticamente, busca a satisfação de seus desejos. (LIPOVETSKY, 2004).

$\mathrm{Na}$ hipermodernidade, os princípios modernos na contemporaneidade são readaptados para "uma sociedade liberal, caracterizada pelo movimento, pela fluidez, pela flexibilidade; indiferente como nunca antes se foi aos grandes princípios estruturantes da modernidade, que precisaram adaptar-se ao ritmo hipermoderno para não desaparecer" (LIPOVETSKY, 2004, p. 24).

A hipermodernidade seria, portanto, a modernidade resultante das incertezas e receios de uma sociedade angustiada com a liberdade de escolha proporcionada pela pósmodernidade e impactada pela aceleração mercantil, consumista e capitalista gerada pelos avanços tecnológicos e dos meios de comunicação de massa. Gilles Lipovetsky (2004) atenta que a hipermodernidade conduz a uma fragmentação da sociedade, dos costumes e do

\footnotetext{
${ }^{4}$ Segundo a concepção de Fredric Jameson, "a pós-modernidade tem sido frequentemente caracterizada (por mim e por várias outras pessoas) como o fim de algo” (JAMESON, 2001, p. 95.)
} 
tradicionalismo, uma exacerbação do consumo, expansão da cultura do hedonismo, do individualismo e da necessidade da urgência de um novo paradigma social na contemporaneidade. A expressão "pós-modernidade" indica uma ruptura com a história do individualismo moderno, assim, a pós-modernidade representa o momento histórico em que todos os freios institucionais que se opunham à emancipação individual desaparecem, dando lugar à manifestação dos desejos subjetivos, da realização individual e do amorpróprio (LIPOVETSK, 2004, p. 23).

Segundo descreve Gilles Lipovetsky (2004), a mutação da modernidade para a pósmodernidade deu-se a partir da metade do século XX e foi iniciada devido o consumo de massa e os valores que este consumo veiculou na sociedade. Com o fim da segunda guerra mundial, surge um novo modo de vida nas sociedades que invade as relações sociais e busca, acima de tudo, a realização do indivíduo em um mundo em que não há limites. Assim, nessa mentalidade urbana, o objetivo do particular consiste na legitimação da realização de si mesmo. A realização pessoal tornou-se um propósito de vida, sendo que todo o interesse dos indivíduos em comunidade, partem de si mesmos. Trata-se de uma verdadeira "atomização ou uma radical perda de socialização sem qualquer semelhança com aquela instituída pela escolarização obrigatória, pela concisão, pela urbanização e pela industrialização do século XIX” (LIPOVETSKY, 2005, p. 84).

Entre 1880 e 1950, os primeiros indícios do surgimento da pós-modernidade entraram, pouco a pouco, em cena. Gilles Lipovetsky (2004) explica que primeiramente a lógica de consumo limitou-se à classe burguesa, sendo que por volta de 1950, surgiu o que denomina de a "segunda fase do consumo", em que a produção e o consumo de massa não estavam mais reservados unicamente a uma classe específica, tornando-se mais disponíveis à toda a sociedade. Esse momento foi seguido por outros movimentos como o individualismo, a libertação de normas tradicionais, o surgimento de uma sociedade cada vez mais voltada para o presente e as novidades que ele traz, cada vez mais tomada por uma lógica de sedução, uma verdadeira cultura da hedonização da vida. Assim, descreve Gilles Lipovetsky (2004, p. 24) que se assistiu a "extensão a todas as camadas sociais do gosto pelas novidades, da promoção do fútil e do frívolo, do culto ao desenvolvimento pessoal e ao bem-estar - em resumo, da ideologia individualista hedonista.”.

A lógica da moda e do consumo permeia os espaços cada vez mais amplos da vida pública e privada, inclusive as áreas não-consumo, como a família. Os tempos atuais são 
modernos, mas com uma exacerbação de certas características das sociedades, como o individualismo, o consumismo, a ética hedonista, a fragmentação do tempo e do espaço, valorizando, no entanto, o reinvestimento afetivo em sentimentos e valores tradicionais, a valorização do amor, a liberdade, a qualidade e a expectativa de vida. Nesse ambiente, "a busca de emoções e prazeres, o cálculo utilitarista, a superficialidade dos vínculos parece ter contaminado o conjunto do corpo social, sem que nem mesmo a espiritualidade escape a isso" (LIPOVETSKY, 2004, p. 8-9, 23, 35).

Aparece a figura dos indivíduos hipermodernos que transmitem um paradoxo. São, "ao mesmo tempo mais informados e mais desestruturados, mais adultos e mais instáveis, menos ideológicos e mais tributários das modas, mais abertos e mais influenciáveis, mais críticos e mais superficiais, mais céticos e menos profundos." (LIPOVETSKY, 2004, p. 27). $\mathrm{Na}$ era contemporânea, o sujeito perde seus referenciais, o indivíduo não tem mais identidade fixa, seus princípios morais e valores sociais não encontram mais lugar onde se fixar (LIPOVETSKY, 2005).

Gilles Lipovetsky, assim como Anthony Giddens, se diferenciam de outros autores que estudam a sociedade contemporânea, pois defende o mundo pós-moderno não como alienação total do indivíduo. Segundo o Gilles Lipovetsky (2005, p. 85), há um controle suave e não totalitário da sociedade por meio do consumo. Os sujeitos adotam os objetos, as modas, as fórmulas de lazer elaboradas por organizações especializadas, porém de acordo com suas conveniências, aceitando isto e não aquilo, combinando livremente os elementos programados".

Para Gilles Lipovetsky (2005, p. 99), a pós-modernidade não é totalmente negativa pois introduz o sujeito em uma estrutura livre dos laços da dependência social e produz indivíduos abertos às escolhas, permitindo a máxima singularização de cada um; um indivíduo mais flexível, livre de estruturas vanguardistas e tradicionais, tolerante, avesso a qualquer forma de exclusão. O pós-modernismo seria um "local" onde todos os estilos, pessoas e visões podem coabitar, sem rigidez de estruturas e pensamentos, proporcionando uma vivência democrática entre todos os indivíduos, ainda que tenham diferentes posições sociais.

Outro pensador da sociedade contemporânea é Boaventura de Sousa Santos (2002) que sugere a pós-modernidade para caracterizar o período de transição decorrente da crise da modernidade, por esta não ter cumprido parte das promessas e ideais - como a liberdade, 
igualdade e fraternidade. Ou, em outros termos, utiliza-se do termo pós-modernidade para indicar uma sociedade baseada nos imperativos da razão e que proporciona os meios para o livre desenvolvimento material e moral de todos a partir do uso também racional dos recursos naturais - dando lugar a problemas sociais que revelam o momento de crise. $\mathrm{O}$ mundo está diante de um fenômeno multifacetado, interligando de modo complexo dimensões econômicas, sociais, culturais, políticas, religiosas e jurídicas.

Zygmunt Bauman $(2001,2004)$ também interpreta a sociedade atual, mas sua reflexão parte da ideia de que a pós-modernidade trata-se de uma "modernidade líquida", em que os ideais, valores e promessas da modernidade não foram cumpridos. Para o autor, 'líquido-moderna' é uma sociedade em que as condições sob as quais agem seus membros mudam em um tempo mais curto do que aquele necessário para a consolidação, em rotinas e hábitos, das formas de agir e ser. A liquidez da vida e da sociedade se alimentam e se revigoram de forma mútua.

Os relacionamentos são marcados pela liquidez e pela lógica do consumo, podendo ser descartados quando não mais desejados. Bauman identifica uma dificuldade de aprofundamento nas relações sociais, em que os indivíduos movidos pelo egoísmo, buscam prazer a todo custo. A dinâmica da pós-modernidade influencia a família. Os conflitos decorrem dessa individualidade. A família que fixou suas bases na igualdade em dignidade, na liberdade e a afetividade, no amor ao próximo, deve-se preocupar-se com as consequências que os conflitos causam aos envolvidos (BAUMAN, 2004).

Adriana Caldas do Rego Freitas Dabus Maluf, citando Mauricio Luis Mizrahi (1998, p. 62-63 Apud MALUF, 2010, p. 26), descreve que na pós-modernidade houve uma segunda revolução individualista, na qual o indivíduo limitado da era moderna cedeu lugar ao individualismo total da era atual. Na pós-modernidade, adotam-se instituições mais flexíveis e abertas, que, recusando as estruturas rígidas, uniformes e hierarquizadas do passado, fazem vigorar o estímulo das necessidades. Ampliam-se a autonomia individual e a valorização da realização pessoal do indivíduo. Nesse sentido, "a pós-modernidade aparece como a democratização do hedonismo".

Embora os pensadores usem conceitos diferentes para discorrer sobre os fenômenos da contemporaneidade, há um fio condutor que une a todos eles, a mudança: “o conceito de pós-modernidade faz parte do pensamento social porque alerta para algumas mudanças sociais e culturais importantes que estão acontecendo neste final de século XX” (LYON, 
1998, p. 9).

A mudança da modernidade à pós-modernidade atingiu a todas as instituições, especialmente a família e os conflitos dentro dela existentes, que é histórica e social, mas nem sempre teve as mesmas características que atualmente. Elisabeth Roudinesco (2003, p. 197) assevera que a família pós-moderna, contemporânea, permanece em um processo de constante reconstrução, ressignificando seus conceitos, tais como o afeto, a paternidade e a filiação. Assim, visualiza-se na família as transformações sentidas e sofridas nos indivíduos com as novas estruturas sociais no momento contemporâneo.

\section{A SOCIEDADE CONTEMPORÂNEA E A COMPLEXIDADE DOS RELACIONAMENTOS: O CONFLITO COMO FENÔMENO INERENTE À HUMANIDADE}

A concepção clássica do conflito era focada no fenômeno como uma espécie de patologia social, um problema que existia entre os indivíduos e que precisava ser extirpado para se chegar em uma sociedade pacífica e em uma relação melhor entre as pessoas. ${ }^{5}$ Teorias modernos superam essa visão negativa do conflito, como algo que deve ser superado, e começam a entendê-lo como um fenômeno constitutivo da vida em sociedade, integrante da humanidade.

Georg Simmel (2009, p. 228) descreve que não haveria como existir uma coletividade em total harmonia e sem nenhuma espécie de conflitos. Esta hipótese para o autor seria totalmente irreal e não manifesta nenhum processo da realidade da vida. Para Simmel, assim como no universo existem forças antagônicas, atrativas e repulsivas, que contribuem para a existência de vida e movimento dentro do planeta, da mesma maneira a

\footnotetext{
${ }^{5}$ Segundo Thomas Hobbes (2000), o homem é o lobo do homem e devido a suas paixões naturais, se forem deixados em um estado de natureza, os homens tendem a viver em constante guerra e conflito, sendo necessário estabelecer um contrato social estabelecendo um poder que os obrigue, por temor à punição, a cumprir os pactos e respeitar as leis da natureza. Esse contrato social é estabelecido pelo Estado por meio de suas leis e busca extirpar o conflito social e garantir a pacificação (HOBBES, 2008, p. 123). Para Jean-Jacques Rousseau (1999), os homens vivem de forma pacífica no estado de natureza, sendo corrompidos pela sociedade. O contrato social defendido por Thomas Hobbes reforçaria as relações sociais desiguais e exploradoras que passam a ser apoiadas pela ciência jurídica e pelo poder estatal. A solução para o conflito social estaria na ideia da vontade geral, na vontade coletiva que deveria ser o fundamento de todo o Direito, assim, ao obedecer a lei, o cidadão estaria agindo de acordo com a sua própria vontade, permanecendo livre. Já para Karl Marx, o conflito trata-se de uma anormalidade histórica causada pela propriedade privada e pela luta de classes. Entendia que com a superação das classes antagônicas, pelo comunismo, estaria superada a origem das guerras sociais e portanto acabaria com os conflitos entre os indivíduos (SILVA, 2005, p. 6).
} 
sociedade necessita uma certa quantidade de harmonia e desarmonia, associação e competição, vontade boa e má. A sociedade existe como resultado de ambas as categorias de interação, que aparecem completamente positivas em relação a ambas (SIMMEL, 2009, p. 228-229).

A história da humanidade foi marcada por grandes conflitos. A pós-modernidade, especialmente, decorre de uma série de conflitos e abalos do sistema da modernidade (BITTAR, 2009, p. 96). Assim, para Germán Silva García (2008, p. 29), o conflito trata-se de um fenômeno natural na sociedade e por esse motivo, não se pode afirmar que o conflito seja necessariamente uma patologia, anomalia social. Com efeito, traduz-se em um fenômeno natural da vida social em que diferentes convivem. Por esse motivo, a qualificação do conflito como algo eminentemente negativo, imoral e reprovável, dependerá do ponto de vista e da ponderação de cada indivíduo e os efeitos que a situação de conflito acarreta à cada envolvido (GARCÍA, 2008, p. 29).

Oliver Ramsbotham, Tom Woodhouse e Hugh Miall (1999, p. 5) interpretam que o conflito é uma expressão da heterogeneidade de interesses, valores e crenças que surgem conforme novas formações geradas pela mudança social vão contra as restrições herdadas. Segundo José Luiz Bolzan de Morais e Fabiana Marion Spengler (2008, p. 54), a contradição e o antagonismo são uma realidade que marca a vida contemporânea, sendo que a organização da sociedade se baseia em relações complexas identificadas por paradoxos e antagonismos desde as relações mais efêmeras às mais duradouras.

José Luiz Bolzan de Morais e Fabiana Marion Spengler (2008, p. 45), esclarecem que a definição de conflito compõe diversas variantes, pois o conflito pode surgir das mais diversas relações sociais, por questões de trabalho, políticas, sociais, étnicas, religiosas ou até familiares. A palavra conflito vem do latim confligere, que significa "chocar junto", o que traduz a ideia de choque, contrapor ideais, pensamentos, ideologias, valores etc.

Segundo Johan Galtung (2007, p. 14-34) a existência de um conflito é necessária que forças conflitantes sejam dinâmicas, contendo em si próprias o sentido da ação, reagindo umas sobre as outras. No conflito, o que estaria em choque são os objetivos de cada indivíduo em que a realização pessoal de um exclui a realização do outro, existindo, portanto, um desacordo, uma contradição. Ao mesmo tempo que a sociedade atual conduz à uma realização pessoal, busca- se esta acima dos interesses da coletividade e por vezes da família.

Giovanni Cosi (2004, p. 3- 
4) afirma que o conflito é uma disputa entre teses e opiniões diversas em torno de um problema, podendo ser encarado como uma situação de confronto, mas que não exclui a possibilidade de comunicação entre as partes e não necessariamente transforma os envolvidos em inimigos.

Johan Galtung (2007, p. 19) descreve que as contradições e os conflitos devem ser bem-vindos e não evitados, porquanto representam oportunidades para expandir os relacionamentos, criar espaços de desenvolvimento da criatividade com novas e factíveis realidades.

O conflito significa crise, sendo que a liberdade constitui tanto uma consequência do conflito como a condição da transformação do conflito. Quanto mais se aproveita a oportunidade da situação conflituosa, mais pode-se exercer a liberdade nas relações. Como descrevem José Luiz Bolzan de Morais e Fabiana Marion Spengler (2008, p. 47), uma sociedade sem conflitos é uma sociedade estática em que os indivíduos não exercem plenamente sua liberdade. Além de enxergá-lo por um ponto de vista negativo e adversarial, o conflito tem a capacidade de unir as pessoas, aproxima as pessoas e os grupos que, de outra maneira, não teriam qualquer relação entre si. Silvia Ozelame Rigo Moschetta (2018, p. 127) explica que o conflito é "congênito às relações humanas, capaz de representar cada sujeito em sua integralidade", mas também é algo natural, entretanto, "não pode ser naturalizado, sob pena de comprometer a integração social”. A situação conflituosa possui dois aspectos, pode ser negativo quando não se consegue vencer as diferenças; por outro lado, pode ser positivo, quando permite que se compreenda a dificuldade, a crise, para assim significá-las.

Os conflitos podem ser considerados reflexos do momento que a sociedade atual vivência. Os indivíduos tendem a encararem maiores embates entre si, nas diversas relações que nutrem. O paradoxo da sociedade pós-moderna consiste no antagonismo existente entre os interesses públicos (no sentido de coletividade, grupo social) e privados (individuais) e na tentativa do sujeito de harmonizá-los. Assim, busca-se realizações pessoais a despeito de interesses de outrem violados. Segundo Andreia Lucia Horta e Silva: "se pensarmos em uma relação padrão, que envolva interações frequentes, com um mínimo de intensidade, e que seja importante para as partes, ela deverá suscitar conflitos em algum momento", pois consiste em um fenômeno natural da humanidade.

Os conflitos existem desde o início da humanidade e evoluem conforme a realidade dos indivíduos, da sociedade. Identifica, portanto, a forma de lidar com os conflitos na pós- 
modernidade é determinante na solução e nas consequências pessoais aos envolvidos, quanto mais aos conflitos familiares, cuja origem denota um aspecto mais pessoal, emocional e psicológico, ainda que existam questões patrimoniais envolvidos, exige um especial tratamento.

\title{
3 A PÓS-MODERNIDADE E OS CONFLITOS FAMILIARES: A MEDIAÇÃO NA PROTEÇÃO INTEGRAL À PESSOA E O RESGUARDO DE DIREITOS DA PERSONALIDADE
}

Rodrigo da Cunha Pereira (2005, p. 3), a respeito do reflexo da pós-modernidade na família, afirma que o Direito de Família, com os novos conflitos, está vivendo situações de contradição e ambiguidade, pois a sociedade está em constante movimento. Assim descreve:

\begin{abstract}
Como já apontou Freud, as relações de família são as mais intrincadas e complexas. São as relações de família que pressupõe a dignidade de cada um de seus membros. Nas relações de família de antigamente, na família hierarquizada, patrimonializada, não se pensava isso. Era muito mais simples. Cada um tinha seu papel estanque. O pai tinha uma função, o filho obedecia calado, a mulher também. Passa a ser complexa quando você dá um lugar de sujeito para cada um de seus membros para questionar seus lugares. E o ser humano é isso, esse complexo de matéria e energia, essa tensão de forças que produz ligamentos e desligamentos que se faz mais forte na intimidade. O lugar da maior intimidade é a família. Daí que eclodem os maiores conflitos.
\end{abstract}

Os indivíduos no contexto familiar contemporâneo convivem em uma sociedade pós- moderna, com características que conduzem à liquidez de relacionamentos e efemeridade, onde prática do consumo passou a interferir em instituições não-consumo, como na família (BAUMAN, 2004; ROUDINESCO, 2003; LIPOVETSKY, 2004).

Adriana Caldas do Rego Freitas Dabus Maluf (2010), explica que a família na pósmodernidade, "se finca num aspecto mais liberal, mais individualista, em que a lei, sentindose impotente para sanar todos os conflitos que surgem, abandona-a às regulamentações mais flexíveis que a sociedade soube se impor fora da autoridade pública".

A família é o ambiente de proteção onde o sujeito é guiado para a vida externa, traça seus objetivos e propósitos e aprende como buscá-los. Consiste no espaço de aprendizado, de desenvolvimento da personalidade e de particularidades individuais. Também é por meio da família que a pessoa fortalece suas habilidades interpessoais e intrapessoais, e potencialidades essenciais que tornam possível o convívio com outrem, que 
por vezes possui diferentes concepções.

A família constitui o primeiro grupo social em que as pessoas conhecem e convivem entre si, sendo essencial para o desenvolvimento da personalidade os indivíduos. Devido sua grande importância social e ao seu papel como instituto fundamental na construção dos valores morais nos indivíduos, a família recebeu uma especial proteção do Estado, constituindo esta proteção um direito público subjetivo. Inclusive, a Declaração Universal dos Direitos do Homem, estabelecida pela ONU, em 1948, trouxe em seu art. 16.3 que "a família é o núcleo natural e fundamental da sociedade e tem direito à proteção da sociedade e do Estado", assim, restou estabelecido nesta norma internacional o papel da sociedade e do Estado na proteção das famílias.

Em virtude das mudanças sociais experimentadas nos últimos anos, especialmente no final do século passado, e no início do atual, a compreensão a respeito da família passou por grandes mudanças, na tentativa de acompanhar a evolução social; contudo, a legislação raramente seguiu o ritmo das modificações sociais. Como bem explica Caio Mário da Silva Pereira (2017, p. 34): “Como organismo natural, a família não acaba. Como organismo jurídico, elabora-se sua nova organização.”. Assim, a Constituição Federal de 1988, em seu artigo 226, buscou introduzir no ordenamento uma nova visão a respeito da família. $\mathrm{O}$ conceito atual de família abrange várias formas de arranjos e, diferentemente do estabelecido no modelo tradicional, reconhece as famílias multiparentais, monoparentais, uniparental, homoparental e design (decorrentes da reprodução humana assistida).

Na oba "Mundo em desordem", Anthony Giddens (2003), descreve que entre as mudanças que ocorrem no mundo, em virtude da modernidade tardia, as mais importantes são aquelas que se verificam no nível do indivíduo, seus relacionamentos e sexualidade. Assim, o relacionamento, o casamento e a família são aspectos sociais que sofrem diretamente o impacto das transformações em nível global, cujas expressões de tais mudanças são perceptíveis no modo como as pessoas estão se relacionando, afinal em quase todos os locais do mundo encontra-se discussões a respeito da igualdade sexual, a regulação dessa sexualidade, a definição e o destino da família.

Durante muitas décadas as mulheres eram vistas apenas como propriedade dos homens, devendo viver somente para a família, submetendo-se à autoridade do homem. A homossexualidade, por muito tempo, foi entendida como uma patologia. Somente a partir de 1950, com o ingresso das mulheres no mercado de trabalho, esse quadro começa a se 
modificar. A nova postura feminina contribui, em grande escala, para as mudanças dentro da estrutura familiar. O casamento passa a ser visto como fundamento no amor romântico e não mais como contrato econômico, motivado por questões puramente patrimoniais. A definição da família mudou. O casal da contemporaneidade passa a ser o cerne da família, desvinculando-se do parentesco. As relações estão fundamentadas na intimidade e na comunicação emocional (GIDDENS, 2003).

De acordo com as estatísticas do IBGE, no relatório de "Estatísticas do Registro Civil de 2018", naquele ano foram registrados 1.053.467 casamentos civis, contra 1.070.376 de 2017, uma redução de 1,6\%. A pesquisa mostra que o casamento entre pessoas do mesmo sexo teve aumento de 61,7\% no ano passado em relação a 2017. Em 2018, foram registrados 9.520 casamentos civis entre cônjuges do mesmo sexo, ante 5.887 no ano anterior. (IBGE, 2018a).

Outro aspecto que demarca a contemporaneidade que foi identificada pelo IBGE em um comparativo entre as estatísticas de 1974 e 2014 que diz respeito à idade média dos cônjuges na data do casamento. Assim, em 1974, a idade média era de 26 anos para os homens e 23 para as mulheres, aumentando em 2014 para 33 anos para os homens e 30 anos para as mulheres. Tal fato está relacionamento com a continuidade dos estudos e a dificuldade na inserção no mercado de trabalho e corrobora a interpretação de Gilles Lipovetsky a respeito do indivíduo hipermoderno, que possui maior qualificação e procura salários mais elevados, condizentes com as suas habilidades profissionais e educacionais. Além dessas questões, tem-se a opção cada vez mais comum pelo convívio em união estável, o que evidencia a tendência de que os vínculos relacionais sejam mais frágeis na pósmodernidade, influenciando a elevação da idade média dos cônjuges solteiros na data do casamento. (IBGE, 2018b).

$\mathrm{Na}$ tentativa de se harmonizar com a atual conjuntura social, a família sofreu reflexos da pós-modernidade em suas relações. Na relação conjugal, por exemplo, tem-se o aumento na taxa de divórcios que conduz ao crescimento do número de processos envolvendo litígios familiares, com discussão de questões atinentes à dissolução conjugal, alimentos entre cônjuges e partilha de bens. O número de divórcios aumentou de 373.216 em 2017 para 385.246 em 2018, crescendo a taxa geral de divórcios de 2,5\% (2017) para 2,6\% (2018). O relatório demonstra que a região Sudeste do país registrou a maior taxa geral de divórcio (3,1\%), que representa cerca de 3 divórcios para cada 1000 habitantes 
com 20 anos ou mais. (IBGE, 2018a). A pesquisa também apontou uma redução na duração dos casamentos. Em 2008, os casamentos duravam, em média, 17 anos. Dez anos depois, em 2018, a média de tempo de duração de casamentos caiu para 14 anos. A idade média de divórcios entre os homens é 43 anos, enquanto as mulheres, 40 anos. 46,6\% das dissoluções aconteceram em famílias com filhos menores de idade; $27,8 \%$ foram entre casais sem filhos; 17,3\%, entre famílias somente com filhos maiores e 7,8\%, entre famílias com filhos menores e maiores de idade. (IBGE, 2018a).

Anthony Giddens interpreta que na modernidade tardia, as crianças tendem a serem mais valorizadas porque a maioria dos casais, por motivos financeiros ou até mesmo profissionais, optam por terem menos filhos ou nenhum. Por outro lado, difundiu-se o conhecimento acerca da reprodução humana assistida, que tornou possível a casais que, de forma natural, não poderiam exercer a paternidade biológica. Além disso, as decisões em ter um filho são guiadas por necessidades psicológicas e emocionais, afinal, como a união conjugal pode representar um risco em que há a possibilidade de divórcio, torna-se preciso pensar o efeito da separação sobre os filhos, observando que a existência de muitas famílias sem a presença de um dos genitores pode apontar efeitos no modo como as crianças crescem, são educadas e se desenvolvem (GIDDENS, 2003). As estatísticas do IBGE demonstram que as mulheres estão tendo filhos mais tarde. Os percentuais de nascimentos cujas mães tinham até 24 anos caíram. Houve elevação nas faixas etárias entre 30 e 44 anos (IBGE, 2018a).

Em relação a guarda compartilhada houve um aumento do percentual de divórcios concedidos em cuja sentença consta a guarda compartilhada dos filhos. Dentre os 166.523 divórcios concedidos para casais com filhos menores, $24,4 \%$ tiveram guarda compartilhada. Mesmo com o avanço, a predominância das mulheres com guarda dos filhos segue, com 65,4\%. (IBGE, 2018a).

As excessivas mudanças ocorridas na família estimulam o desenvolvimento de conflitos familiares, em decorrência da liquidez e efemeridade dos relacionamentos. De fato, a família, ao longo dos anos, enfrenta um processo de profunda transformação em virtude dos fatores econômicos, sociais e culturais em decorrência destas transformações, vários novos tipos de conflitos apresentam- se na relação familiar, já que a família atual é inovadora, democrática e igualitária. Como consequência dessa nova definição de família e da complexidade da sociedade atual, surgiram conflitos e demandas familiares que até então 
não eram discutidas no âmbito do Direito.

Os conflitos são inerentes às relações humanas, justamente porque as pessoas são diferentes umas das outras, provêm de contextos familiares e culturais diversos. Em uma sociedade pós-moderna não há como evitar que os conflitos ocorram, especialmente aqueles decorrentes de relações tão íntimas como no caso das relações familiares. A família atual, mais democrática e igualitária, possibilita a convivência entre diferentes pessoas, o que torna o conflito na relação familiar, inevitável. Essa divergência não é essencialmente negativa ou positiva, simplesmente, é da natureza das relações humanas. Assim, "o que torna o conflito construtivo para os envolvidos, levando-se para uma situação mais ou menos desejável em termos relacionais, é a forma de lidar com ele” (MOSCHETTA, 2018, p. 120-121).

A pós-modernidade representa em determinados aspectos, a liquidez das relações, a efemeridade dos sentimentos, a busca instintiva e até animalesca pelo prazer, sem a ponderação das consequências de ações tomadas, o desenvolvimento de um indivíduo narcísico marcado pela contradição, de um lado, preparado aos novos desafios, antenado quanto às tecnologias, eficiente, produtivo e empreendedor, e do outro, com dificuldades de manter relações duradouras, que sofre com males como ansiedade, estresse, traumas, doenças psicossomáticas, cada vez mais dependente de medicamentos e terapias - que atuam em alguns casos como um meio de fuga -, frágil em suas emoções e sentimentos.

Com efeito, existem autores que entendem que a pós-modernidade proporcionou a abertura a novas formações familiares, baseado nos ideais de respeito e igualdade. Anthony Giddens, por exemplo, compreende que determinados valores que reinavam na modernidade, como a ideia de direitos humanos, não estão perto de cair no consumismo puro. Ao mundo do consumo escapam também outros valores, como a preocupação com a verdade ou com o relacional” (GIDDENS, 1991, p. 35; LIPOVETSKY, 2004)

A forma como esses conflitos são tratados poderá reduzir os efeitos dos conflitos na pós-modernidade, especialmente dos familiares, prevenindo contra violações à dignidade humana e aos direitos da personalidade, é a forma como estes conflitos são tratados, conduzidos. Muitas das vezes os conflitos são deixados de lado, ignorados, até que não exista outro caminho senão o fim da relação. Os indivíduos da sociedade atual, por vezes, assoberbados de si mesmos, deixam de enfrentar questões que realmente importam, como o futuro da família; ou como será conduzido o relacionamento; as dificuldades na convivência entre casal; os desafios e as responsabilidades decorrentes de uma paternidade inesperada, 
dentre outras questões.

A forma de se enfrentar e até mesmo resolver os conflitos, na pós-modernidade "[...] pode determinar a diferença nas soluções dos impasses surgidos das relações entre as pessoas no meio familiar, profissional e social" (THOMÉ, 2018, p. 114). Cabe ao Poder Judiciário a solução do litígio familiar, como detentor da legitimidade estatal para responder juridicamente às demandas, entretanto, nem sempre o Judiciário enfrenta todas as questões envolvidas no conflito familiar, decorrente de relações complexas como as atuais. Não cabe ao Judiciário a análise de questões subjetivas, que envolvam emoções, desejos, aflições e angústias das partes, mas apenas a decisão do processo, colocando fim à lide. Contudo, em muitas situações e especialmente nas relações pós-modernas, o conflito tem origem de questões internas, subjetivas dos indivíduos, refletindo no mundo jurídico.

Liane Maria Busnello Thomé (2018, p. 114), a esse respeito, explica que o Poder Judiciário não possui a legitimidade para “[...] oferecer atenção às carências emocionais das partes envolvidas em conflitos, principalmente familiares, como frustrações, abandonos, honra e respeito, que são aspectos subjetivos das pessoas [...]”, que quando tornam-se em um conflito jurídico, “[...] acarretam disputa judicial, compensação financeira, como se constata nos longos processos litigiosos de separação, dissolução de união estável e divórcio [...]" que conduzem a discussões acerca da guarda, convivência e alimentos para os cônjuges, para os filhos menores de idade ou incapazes e na partilha de bens.

O ideal é que o conflito seja conduzido e a resolução buscada com a técnica adequada de gestão de conflitos, sendo que o Poder Judiciário compõe uma das possibilidades (MARINONI, ARENHART, MITIDIERO, 2017). Se o mecanismo de condução do conflito na busca de uma solução é inadequado ou ineficaz para a situação, correse o risco de que os efeitos destrutivos deste sejam perpetuados na sociedade (KEPPEN, MARTINS, 2009).

A mediação entrou oficialmente no cenário jurídico com a Resolução de 125/2010 do Conselho Nacional de Justiça (CNJ) que dispõe acerca da política judiciária nacional de tratamento adequado dos conflitos de interesses, estabelecendo além da mediação outros métodos de resolução de conflitos, como a conciliação e a possibilidade da utilização de novas técnicas no Poder Judiciário, como a constelação. O Código de Processo Civil de 2015, seguindo a tendência do CNJ, estimulou a decisão consensual dentro do processo de família, instituindo obrigatoriamente a audiência de mediação. 
Conforme explica Bruna Schlindwein Zeni e Taise Rabelo Dutra Trentin, (2010, p. 90- 91), devido transformações sociais ocorridas no período moderno, tornou-se incompatível com a dinâmica e a instabilidade das relações sociais contemporâneas, como a inserção da mulher no mercado de trabalho fruto dos movimentos feministas, o avanço das tecnologia e a globalização que aumentaram o ritmo e a rapidez das informações propagadas no mundo, todos estes fenômenos, tornaram a família incompatível com a dinâmica e a instabilidade das relações contemporâneas e seus conflitos. Assim surge a urgência fazer uso de outras técnicas pra resolução dos conflitos familiares, visando a proteção da dignidade da pessoa humana e de direitos essenciais como os direitos da personalidade.

A mediação busca a solução do conflito por meio da comunicação não violenta e direta entre os indivíduos. As partes encontram na figura do mediador um facilitador da comunicação, que terá o papel de identificar interesses semelhantes entre os envolvidos, para que alcancem a um acordo, levando em consideração as necessidades de cada um, que seja sustentável - principalmente se existem filhos na relação - e proporcione a pacificação para as partes (TARTUCE, 2018).

O processo de mediação contribui para relação familiar, pois consoante asseveram Bruna Schlindwein Zeni e Taise Rabelo Dutra Trentin, (2010, p. 94), estimula as partes a tornarem-se colaboradores ao invés de litigantes, melhorando a comunicação entre elas ao propor uma escuta menos defensiva ou de ataque, o que conduz à maior confiança das partes em relação a si mesmas e ao processo, "o que acaba por diminuir efetivamente os conflitos identificados melhorando o respeito e assistência dentro da família".

É na família que os modelos de relacionamento são aprendidos e utilizados nas relações sociais, e a mediação pode transmitir valores de respeito ao próximo, de solidariedade, de autodeterminação e estímulo ao exercício da cidadania (THOMÉ, 2018, p. 127). Assim, a mediação familiar devolve aos indivíduos a capacidade de assumir a responsabilidade por seus atos, consiste em um procedimento que oportuniza o fortalecimento de laços, em uma sociedade que encontra dificuldades em desenvolver relacionamentos profundos.

\section{CONCLUSÕES}

A pós-modernidade, também denominada de modernidade tardia, 
hipermodernidade, modernidade líquida, representa um momento em que as barreiras que envolviam o momento anterior (modernidade) foram transpostas, em que o indivíduo busca sua realização máxima e pessoal. Como consequência, os conflitos dentro das relações sociais tendem a aumentar e evoluir de questões simples para questões complexas, o que marca a complexidade dentro das relações pós-modernas.

O fenômeno da modernidade e da pós-modernidade e seus reflexos no mundo contemporâneo conduzem a um momento em que estruturas tradicionais são substituídas por novas - devido especialmente à separação entre tempo e espaço causado pelas novas tecnologias -, onde a lógica de consumo avança em instituições de não-consumo e o sujeito torna-se cada vez mais desejoso por sua realização pessoal e particular, assumindo relacionamentos superficiais e descartáveis. A sociedade contemporânea é marcada pela dificuldade na busca de consenso e de soluções para problemas comuns, tarefa que envolve o fim da desigualdade e da exploração e uma nova construção de princípios éticos, morais locais e globais. O grande dilema reside na conciliação das escolhas e possibilidades individuais com um futuro comum, em uma sociedade cada vez mais produto de uma lógica mercantilizada e excludente. Como uma hipermodernidade que transmite um paradoxo nas relações sociais, em que o indivíduo busca, ao mesmo tempo, seu interesse individual e de outrem.

O conflito era identificado pela sociedade como uma patologia, anomalia social, algo que trazia apenas destruição para as relações. Na contemporaneidade o conflito assumiu o significado de crise mais oportunidade. Identificado como um fenômeno natural da humanidade, a situação conflituosa possibilita a criação de novas e criativas realidades diante os desconfortos da relação.

Os reflexos das mudanças culturais e sociais na pós-modernidade na relação familiar, em particular o surgimento de conflitos familiares que dão ensejo aos processos judiciais, - as partes transferem ao Estado a responsabilidade de resolver os litígios - e protagonizam as grandes demandas do Poder Judiciário. Como forma de proteção integral a pessoa e resguardo à dignidade da pessoa humana, a mediação é um método de solução de conflitos que decorrem da sociedade pós-moderna, proporcionando a pacificação familiar e social. A questão em preeminente análise no presente artigo está no fato de que a pósmodernidade revela que os sujeitos não sabem lidar com seus conflitos. A dificuldade encontrada na sociedade contemporânea é justamente na forma de lidar com os conflitos, que 
pode acarretar prejuízos a toda a sociedade.

Os conflitos familiares são dotados de alta carga emocional e subjetividade. Decorrem da relação familiar, e levam ao Poder Judiciário em busca de solução. Contudo nem sempre uma sentença judicial resolve os conflitos familiares, os conflitos emocionais e desentendimentos se perpetuam trazendo dor e prejuízo emocional para toda a família.

A família contemporânea passa por transformações com o crescimento em quantidade e extensão dos conflitos. Ao mesmo tempo que se depara com uma família aberta à possiblidades, que se expandiu para salvaguardar a afetividade, descobre-se que esta mesma família sofre reflexos da pós-modernidade, como demonstrado nas estatísticas.

Os conflitos são inerentes às relações humanas, pois as pessoas que integram as relações sociais são diferentes umas das outras, provêm de contextos familiares e culturais diversos. Em uma sociedade pós-moderna não há como evitar que os conflitos ocorram, especialmente aqueles decorrentes de relações tão íntimas quanto aos familiares. A família atual, mais democrática e igualitária possibilita a convivência entre diferentes pessoas, o que torna o conflito na relação familiar, inevitável. Essa divergência não é essencialmente negativa ou positiva, simplesmente, é da natureza das relações humanas. Embora a pósmodernidade indique a liquidez das relações, a efemeridade dos sentimentos, a busca instintiva e até animalesca pelo prazer, sem a ponderação das consequências de ações tomadas, pôde-se compreender que a pós-modernidade deu vazão à aceitação do diferente na relação familiar, o que por lógica aumentam os conflitos, em quantidade e qualidade.

Na busca de proteger a pessoa humana e evitar que os efeitos dos conflitos na pósmodernidade sejam prejudiciais, a mediação surge como uma possibilidade para a sociedade pós-moderna resolver seus conflitos de forma a proporcionar a pacificação entre os indivíduos, a justiça nas relações, e, cumprir com os objetivos da República Federativa do Brasil. Por esse motivo, a mediação oportuniza a proteção integral da pessoa, o resguardo a questões atinentes aos direitos da personalidade, envolvendo emoções, aspectos pessoais e íntimos quanto às relações familiares.

\section{REFERÊNCIAS}

BAUMAN, Zygmunt. Amor Líquido. Sobre a fragilidade dos laços humanos. Rio de Janeiro: Zahar, 2004. 
2001.

, Zygmunt. Modernidade líquida. Trad. Plínio Dentzien. Rio de Janeiro: Zahar,

, Zygmunt. Vida Líquida. Rio de Janeiro: Zahar, 2007.

BITTAR, Eduardo Carlos Bianca. O direito na pós-modernidade e reflexões frankfurtianas. 2. ed. Rio de Janeiro: Forense, 2009, p. 96.

COSI, Giovanni. Interessi, diritti, potere: gestioni dei conflitti e mediazione. Ars Interpretandi, Padova, n. 9, 2004.

GALTUNG, Johan. Introduction: peace by peaceful conflict transformation - the TRANSCEND approach. In: WEBEL, Charles; GALTUNG, Johan (Ed.). Handbook of Peace and Conflict Studies. London; New York: Routledge, 2007. p. 14-34.

GARCÍA, Germán Silva. La Teoría del Conflicto: Un marco teórico necesario.

Prolegómenos: Derechos y Valores, Bogotá, v. 11, n. 22, p. 29-53, jul./dez. 2008.

GIDDENS, Anthony. As consequências da modernidade. Trad. Raul Fiker. São Paulo: Unesp, 1991.

, Anthony. Modernidade e identidade. Rio de Janeiro: Zahar, 2002.

, Anthony. Mundo em descontrole. 3. ed. Trad. Maria Luiza X. de A. Borges. Rio de Janeiro: Record, 2003.

HOBBES, Thomas. Leviatã ou a matéria, forma e poder de um estado eclesiástico e civil. 3. ed. São Paulo: Ícone, 2008.

, Thomas. De Cive. Madrid: Alianza, 2000.

IBGE. Estatísticas do Registro Civil (referente ao ano de 2018). Rio de Janeiro: IBGE, v. 45, p. 1-8, 2018.

Estatísticas do Registro Civil (referente ao ano de 2014). Rio de Janeiro: IBGE, v. 41, p. 1-82, 2014.

JAMESON, Fredric. A Cultura do Dinheiro. Petrópolis: Vozes: 2001.

KEPPEN, Luiz Fernando Tomasi; MARTINS, Nadia Bevilaqua. Introdução à resolução alternativa de conflitos: negociação, mediação, levantamento de fatos, avaliação técnica independente [...] Curitiba: JM Livraria Jurídica, 2009.

LIPOVETSKY, Gilles. Os tempos hipermodernos. Trad. Mário Vilela. São Paulo:

Barcarolla, 2004.

MALUF, Adriana Caldas do Rego Freitas Dabus. Novas modalidades de família na pósmodernidade. São Paulo: Atlas, 2010. 
MARINONI, Luiz Guilherme; ARENHART, Sergio Cruz; MITIDIERO, Daniel. Novo curso de processo civil: teoria do processo civil, 3 ed. São Paulo: RT, 2017, v. 1.

MORAIS, José Luiz Bolzan de; SPENGLER, Fabiana Marion. Mediação e Arbitragem: Alternativas à Jurisdição! 2. ed. Porto Alegre: Livraria do Advogado, 2008.

MOSCHETTA, Silvia Ozelame Rigo. Teoria pós-moderna do direito de família: a mediação como prática interventivo-participativa na dimensão do pluralismo jurídico. Rio de Janeiro: Lumen Juris, 2018.

PEREIRA, Caio Mário da Silva. Instituições de direito civil. 25. ed. Rio de Janeiro: Forense, 2017, v. V.

PEREIRA, Rodrigo da Cunha. DIGNIDADE em Família. Boletim IBDFAM, Porto Alegre, n. 34, set./out., 2005, p. 3.

RAMSBOTHAM, Oliver; WOODHOUSE, Tom; MIALL, Hugh. Contemporary Conflict Resolution. Cambridge: Polity, 1999.

ROUDINESCO, Elisabeth. A família em desordem. Trad. André Telles. Rio de Janeiro: Zahar, 2003.

ROUSSEAU, Jean-Jacques. O Contrato Social. 3. ed. São Paulo: Martins Fontes, 1999.

SANTOS, Boaventura de Sousa. Pela Mão de Alice: O social e o político na pósmodernidade. 8. ed. Porto: Afrontamento, 2002.

SILVA, Adriana dos Santos. Acesso à Justiça e arbitragem: um caminho para a crise do judiciário. Barueri: Manole, 2005.

SILVA, Andreia Lucia Horta e Silva. Administração de conflitos familiares sob a ótica da Antropologia Jurídica. Teoria e Cultura. UFMG. Juiz de Fora, v. 7, n. 1/2, p. 11 a 20, jan./dez. 2012.

SIMMEL, Georg. Sociologia. Organização de Evaristo de Moraes Filho. São Paulo: Ática, 1983. 2009. v. 1 .

, Georg. Sociology: inquiries into the construction of social forms. Leiden; Boston:

TARTUCE, Fernanda. Mediação nos conflitos civis. 4 ed. Rio de Janeiro: Forense. São Paulo: Método, 2018.

THOMÉ, Liane Maria Busnello. Dignidade da pessoa humana e mediação familiar. 2. ed. com as atualizações do Código de Processo Civil de 2015. Porto Alegre: Livraria do Advogado, 2018. 
ZENI, Bruna Schlindwein; TRENTIN, Taise Rabelo Dutra. Mediação: instituto democrático dialógico de exercício de cidadania na construção de soluções satisfatórias nos conflitos familiares. Revista Direito e Práxis, [S.1.], v. 1, n. 1, p. 80-99, dez. 2010. 